\title{
Prenatal exposure to serotonin reuptake inhibitor antidepressants and childhood behavior
}

\author{
Gillian E. Hanley', Ursula Brain ${ }^{3}$ and Tim F. Oberlander ${ }^{2,3}$
}

BACKGROUND: Animal research has suggested that prenatal serotonin reuptake inhibitor (SRI) antidepressant exposure causes increased anxiety-like behaviors in adulthood. We examined whether in utero SRI exposure influenced externalizing and internalizing behaviors in children at $3 \mathrm{y}$ and again at 6 y of age.

Methods: We recruited women in their second trimester of pregnancy from primary maternity care providers in Vancouver British Columbia, Canada. We compared the internalizing, externalizing, and the anxious and attention subscales of the internalizing behaviors scores of children exposed to SRIs and children not exposed to SRls at age 3 and age 6 .

Results: We included 110 mother-child pairs (44 exposed to SRI and 66 not exposed). Higher levels of internalizing and anxious behaviors were reported in SRI exposed children at both 3 and $6 y$ of age compared with children who were not exposed $(F=7.52, P=0.0072$ and $F=7.91, P=0.0058$, respectively). The fully adjusted hierarchical regression models indicated a positive and significant relationship between SRI exposure and increased internalizing and anxious behaviors even when controlling for maternal mood during pregnancy, postpartum and childhood.

Conclusion: SRI exposure was associated with sustained higher levels of internalizing behaviors in early childhood even when controlling for maternal depression.

T he need to manage maternal depression during pregnancy has been well established, yet conflicting evidence regarding the developmental consequences of use of serotonin reuptake inhibitor antidepressants (SRIs) during pregnancy $(1,2)$ continues to cause uncertainty about how to manage antenatal maternal mood disturbances while minimizing the risks associated with exposure to maternal depression. Up to $20 \%$ of mothers experience antenatal depression and anxiety disorders and 5-8\% of infants are born with in utero exposure to SRIs (3).

SRIs include both selective serotonin reuptake inhibitors (SSRI) and serotonin norepinephrine reuptake inhibitors (fluoxetine, paroxetine, sertraline,citalopram, and venlafaxine, respectively). SRIs inhibit the reuptake of serotonin (5HT), via $5 \mathrm{HT}$ transporter blockade at presynaptic neurons, thereby increasing synaptic 5HT concentrations. Long before birth, serotonin plays a key developmental role in regulating neuronal proliferation, differentiation, migration, and synaptogenesis (4). Central to our understanding of how prenatal SRI exposure might influence early brain development is an appreciation of the diverse role played by the neurotransmitter $5 \mathrm{HT}$. Before 5HT becomes a neurotransmitter in the mature brain, it plays a role as a neurodevelopmental signal, regulating cells and influencing serotonin receptor growth (5). Given that SRIs readily cross the placenta (6) and presumably alter central 5HT levels during critical periods of development, in utero exposure to SRIs may influence behavioral outcomes during childhood.

Genetic and early-life pharmacological manipulations of $5 \mathrm{HT}$ levels in animal models reveal a link between developmental changes in 5HT and anxious behaviors later in life (7). In mice, fluoxetine increases anxiety-like behavior when early SRI exposure occurs within a specific developmental time frame, akin to the human third trimester. Similar manipulations, analogous to SRI exposure, in animal models where genetically absent 5HT transporter molecules increase intrasynaptic 5HT, also lead to adult onset of depression and anxiety-like behaviors (8). As SRI exposed animals mature they demonstrate decreased serotonergic tone, possibly reflecting prolonged activation of inhibitory receptors (i.e., $5 \mathrm{HT}_{1 \mathrm{a}}$ ) (9). Together these findings suggest that altered 5HT auto-inhibitory feedback in the presence of high serotonergic tone (i.e., secondary to SRI exposure or genetically absent $5 \mathrm{HT}$ transporter (5HTT) protein) results in a constrained maturation and function of the 5HT system in ways that paradoxically link prenatal SRI exposure with an increased risk for affective disorders later in life $(10,11)$. To date, there is a remarkable paucity of human studies of childhood outcomes following fetal modulation of 5HTT functions or exposure to high 5HT levels during fetal brain development.

To further examine the behavioral effects of in utero SRI exposure, we undertook the following study of internalizing, and externalizing behaviors at an early school age. Longitudinal maternal reports of child behavior at 3 and 6 y were compared between children with and without in utero SRI antidepressant 
Table 1. Maternal characteristics

\begin{tabular}{|c|c|c|c|}
\hline Variables & $\begin{array}{l}\text { Not exposed } \\
\text { to } S R I(N=66)\end{array}$ & $\begin{array}{l}\text { Exposed to } \\
\text { SRI }(N=44)\end{array}$ & $P$ value \\
\hline $\begin{array}{l}\text { Maternal age at delivery, } \\
\text { years (SD) }\end{array}$ & $33.6(4.6)$ & $32.7(5.0)$ & 0.335 \\
\hline $\begin{array}{l}\text { Gestational age when } \\
\text { enrolled, weeks (SD) }\end{array}$ & $26.7(3.1)$ & $25.0(4.5)$ & 0.003 \\
\hline \multicolumn{4}{|l|}{ Maternal education, $n(\%)$} \\
\hline High school or less & $2(3.0)$ & $4(9.1)$ & \\
\hline Some postsec & $13(19.7)$ & $18(40.9)$ & \\
\hline Postsec completed & $29(43.9)$ & $15(34.1)$ & \\
\hline Postgraduate & $22(33.3)$ & $7(15.9)$ & 0.022 \\
\hline $\begin{array}{l}\text { Maternal alcohol use across } \\
\text { pregnancy, } n(\%)\end{array}$ & $31(47.0)$ & $21(47.7)$ & 0.938 \\
\hline Avg \# drinks served (SD) & $2.79(5.3)$ & $3.2(7.0)$ & 0.711 \\
\hline \multicolumn{4}{|l|}{ Maternal mental health } \\
\hline \multicolumn{4}{|l|}{ Diagnosis at study entry } \\
\hline Anxiety & $13(19.7)$ & $33(75.0)$ & $<0.001$ \\
\hline Depression & $10(15.2)$ & $34(77.3)$ & $<0.001$ \\
\hline $\begin{array}{l}\text { Use of other psychotropic } \\
\text { medicine, } n(\%)\end{array}$ & $2(3.0)$ & $9(20.5)$ & 0.003 \\
\hline HAMD at enrollment (SD) & $5.5(6.3)$ & $11.3(6.1)$ & $<0.001$ \\
\hline HAMD 36 wk gestation (SD) & $4.2(4.1)$ & $9.8(6.2)$ & $<0.001$ \\
\hline HAMD 6 mo (SD) & $4.7(3.4)$ & $8.5(6.4)$ & 0.002 \\
\hline Beck D 3 y (SD) & $6.0(4.3)$ & $11.3(8.3)$ & 0.001 \\
\hline HAMD 6 y (SD) & $6.3(4.7)$ & $11.7(7.2)$ & 0.001 \\
\hline HAMA at enrollment (SD) & $6.1(6.0)$ & $12.7(7.2$ & $<0.001$ \\
\hline HAMA 36 wk gestation (SD) & $6.1(4.6)$ & $11.0(6.8)$ & $<0.001$ \\
\hline HAMA 6 mo (SD) & $4.7(4.4)$ & $10.0(7.0)$ & $<0.001$ \\
\hline Beck A 3 y (SD) & $4.2(4.2)$ & $8.3(6.3)$ & $<0.001$ \\
\hline HAMA 6 y (SD) & $6.3(5.8)$ & $10.6(6.5)$ & $<0.001$ \\
\hline
\end{tabular}

HAMA, Hamilton Rating Scale for Anxiety; HAMD, Hamilton Rating Scale for Depression; SRI, serotonin reuptake inhibitor.

exposure. Based on preclinical models and our previous findings, we expected increased levels of internalizing behaviors in the SRI exposed children even when controlling for the effect of prenatal and concurrent levels of maternal depression and anxiety. Thus, to further examine hypothesized differences in internalizing behaviors, we also examined whether these effects were primarily driven by differences in anxious behaviors (as the animal models suggest) or differences in attention problems.

\section{RESULTS}

\section{Maternal and Neonatal Characteristics}

Maternal characteristics were similar across exposure groups with the exception that mothers treated with an SRI during pregnancy were recruited earlier in pregnancy $(25.0 \mathrm{vs} .26 .7 \mathrm{wk}$, $P=0.003$ ), were slightly less educated with half of exposed mothers having completed some postsecondary or less compared to $22.7 \%$ of unexposed mothers $(P=0.022)$, were more likely to have used other psychotropic medicines, and had significantly higher scores on the scales measuring depression
Table 2. Infant and child characteristics

\begin{tabular}{|c|c|c|c|}
\hline Variable & $\begin{array}{l}\text { Not exposed } \\
\text { to } S R I(N=66)\end{array}$ & $\begin{array}{l}\text { Exposed to } \\
\text { SRI }(N=44)\end{array}$ & $P$ value \\
\hline \multicolumn{4}{|l|}{ Neonatal characteristics } \\
\hline $\begin{array}{l}\text { Gestational age at birth, } \\
\text { weeks (SD) }\end{array}$ & $40.1(1.3)$ & $39.1(1.6)$ & 0.001 \\
\hline $\begin{array}{l}\text { Preterm birth (<37 wk), } \\
n(\%)\end{array}$ & $2(3.0)$ & $6(13.6)$ & 0.036 \\
\hline \multicolumn{4}{|l|}{ Sex, $n(\%)$} \\
\hline Male & $29(43.9)$ & $14(31.8)$ & \\
\hline Female & $37(56.1)$ & $30(68.2)$ & 0.202 \\
\hline \multicolumn{4}{|l|}{ Delivery mode, $n(\%)$} \\
\hline Cesarean section & $18(27.3)$ & $17(38.6)$ & 0.210 \\
\hline Vaginal & $48(72.7)$ & $27(61.4)$ & \\
\hline Birth weight, g (SD) & $3575.0(516.0)$ & $3214.6(491.6)$ & $<0.001$ \\
\hline Birth length, cm (SD) & $51.8(2.8)$ & $50.3(2.5)$ & 0.006 \\
\hline \multicolumn{4}{|l|}{ Apgar scores $n,<7$, (\%) } \\
\hline $1 \mathrm{~min}$ & $6(9.1)$ & $12(27.3)$ & 0.012 \\
\hline $5 \min$ & $0(0)$ & $1(2.3)$ & 0.219 \\
\hline \multicolumn{4}{|c|}{ Postnatal adaptation syndrome symptoms, $n(\%)$} \\
\hline Rapid breathing & $12(18.2)$ & $9(20.5)$ & 0.766 \\
\hline Respiratory distress & $4(6.1)$ & $5(11.4)$ & 0.320 \\
\hline Jittery & $3(4.6)$ & $14(31.8)$ & $<0.001$ \\
\hline Abnormal tone & $0(0)$ & $5(11.4)$ & 0.005 \\
\hline \multicolumn{4}{|l|}{ Child characteristics } \\
\hline $\begin{array}{l}\text { Age at } 3 \text { y study, } \\
\text { years (SD) }\end{array}$ & $3.5(0.64)$ & $3.9(0.65)$ & 0.003 \\
\hline $\begin{array}{l}\text { Age at } 6 \text { y study, } \\
\text { years (SD) }\end{array}$ & $5.9(0.55)$ & $6.2(0.72)$ & 0.016 \\
\hline Weight at $6 \mathrm{y}, \mathrm{kg}(\mathrm{SD})$ & $21.8(5.0)$ & $20.76(3.1)$ & 0.249 \\
\hline Height at $6 \mathrm{y}, \mathrm{cm}(\mathrm{SD})$ & $116.3(5.4)$ & $116.0(6.4)$ & 0.789 \\
\hline $\begin{array}{l}\text { Head circumference at } 6 \\
y, c m(S D)\end{array}$ & $51.4(2.3)$ & $51.7(1.9)$ & 0.409 \\
\hline $\begin{array}{l}\text { Waist circumference at } \\
6 \text { y study, cm (SD) }\end{array}$ & $54.5(3.8)$ & $54.2(4.3)$ & 0.733 \\
\hline $\begin{array}{l}\text { Health problems at } 6 \\
y, n(\%)\end{array}$ & $16(24.2)$ & $18(40.9)$ & 0.064 \\
\hline $\begin{array}{l}\text { Developmental } \\
\text { concerns at } 6 \text { y, } n \text { (\%) }\end{array}$ & $32(48.5)$ & $27(61.4)$ & 0.185 \\
\hline Mother on SRI at $6 y$ & $5(7.6)$ & $32(72.7)$ & $<0.001$ \\
\hline
\end{tabular}

SRI, serotonin reuptake inhibitor.

and anxiety at all time points (Table 1). The majority of mothers were already on an SRI at conception and had previously had a diagnosis of depression and/or anxiety. Approximately half of the women in our cohort reported consuming alcohol at some point during their pregnancy (47\%); however, among this $47 \%$ of women, the mean number of servings consumed across the entire pregnancy was 6.4 , suggesting very little total alcohol consumption. Servings were defined as 12 ounces of beer, $5 \mathrm{oz}$ of wine, or $1.5 \mathrm{oz}$ of spirits. Alcohol consumption did not differ significantly by exposure status. 


\section{Articles | Hanleyet al.}

Neonates who were exposed to SRIs in utero were more likely to be born preterm ( 13.6 vs. $3.0 \%, P=0.036)$ and at an earlier gestational age (39.1 wk gestational age vs. $40.1 \mathrm{wk}, P=0.001)$,

Table 3. Crude CBCL and HBQ-P scores by exposure status

\begin{tabular}{lccc}
\hline Variables, mean (SD) & $\begin{array}{c}\text { Not exposed } \\
\text { to SRI }(N=66)\end{array}$ & $\begin{array}{c}\text { Exposed to } \\
\text { SRI }(N=44)\end{array}$ & Pvalue \\
\hline CBCL at 3y & & & \\
Externalizing behaviors & $46.67(8.39)$ & $45.73(12.35)$ & 0.635 \\
$\quad$ Above threshold, $n$ (\%) & $2(3.0)$ & $1(2.3)$ & 0.811 \\
Internalizing behaviors & $45.70(8.20)$ & $50.25(12.6)$ & 0.023 \\
$\quad$ Above threshold, $n(\%)$ & $1(1.5)$ & $7(15.9)$ & 0.004 \\
Anxious/depressed & $1.23(1.59)$ & $2.45(2.64)$ & 0.003 \\
Attention problems & $1.55(1.56)$ & $1.68(1.47)$ & 0.647 \\
HBQ at 6y & & & \\
Externalizing behaviors & $0.29(0.22)$ & $0.26(0.20)$ & 0.530 \\
$\quad$ Above threshold, $n(\%)$ & $5(7.6)$ & $2(4.6)$ & 0.524 \\
Internalizing behaviors & $0.29(0.21)$ & $0.39(0.28)$ & 0.037 \\
$\quad$ Above threshold, $n(\%)$ & $2(3.0)$ & $6(13.6)$ & 0.036 \\
Overanxious & $0.38(0.26)$ & $0.46(0.32)$ & 0.127 \\
Inattention & $0.61(0.40)$ & $0.53(0.41)$ & 0.305 \\
\hline
\end{tabular}

$\mathrm{CBCL}$, Child Behavior Checklist; $\mathrm{HBQ}$, Health and Behavior Questionnaire.
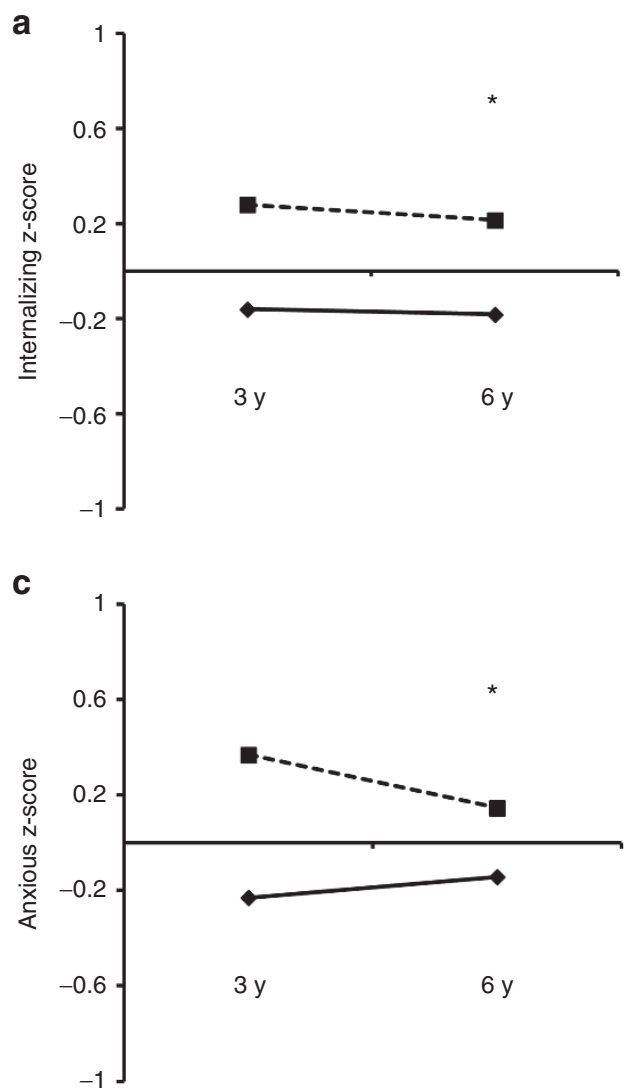

they were smaller both in terms of weight $(3,214.6 \pm 491.6$ vs. $3,575.0 \pm 516.0, P<0.001)$ and length $(50.3 \pm 2.5$ vs. $51.8 \pm 2.8, P=0.006)$, were significantly more likely to have an Apgar score $<7$ at $1 \mathrm{~min}(27.3$ vs. 9.1\%, $P=0.012)$ and were more likely to have been jittery after delivery (31.8 vs. $4.6 \%$, $P<0.001$ ) (Table 2). Unexposed children also completed their follow-up visits or data collection at a younger age $(P=0.003$ and 0.016 respectively).

\section{Childhood Behavioral Outcomes: 3 and 6 y}

At $3 \mathrm{y}$, exposed children had higher levels of internalizing behavior and the anxious/depressed symptoms $(50.25 \pm 12.6$ vs. $45.7 \pm 8.2, P=0.023$, and $2.45 \pm 2.64$ vs. $1.23 \pm 1.5, P=0.003$, respectively) (Table 3 ). They were also more likely to meet a clinical threshold for internalizing behaviors (15.9 vs. $1.5 \%$, $P=0.004)$. Similarly, at 6 y of age, exposed children continued to have significantly higher levels of internalizing behaviors (HBQ-P: $0.39 \pm 0.28$ vs. $0.29 \pm 0.21, P=0.037$ ) and were still more likely to exceed clinical thresholds for internalizing behaviors (13.6 vs. 3.0\%, $P=0.036$ ). Differences in the anxious subscale of the HBQ-P did not reach significance at 6 y of age, and there were no significant differences in the externalizing or attention scales at either 3 or 6 y of age between prenatal SRI exposure groups. b

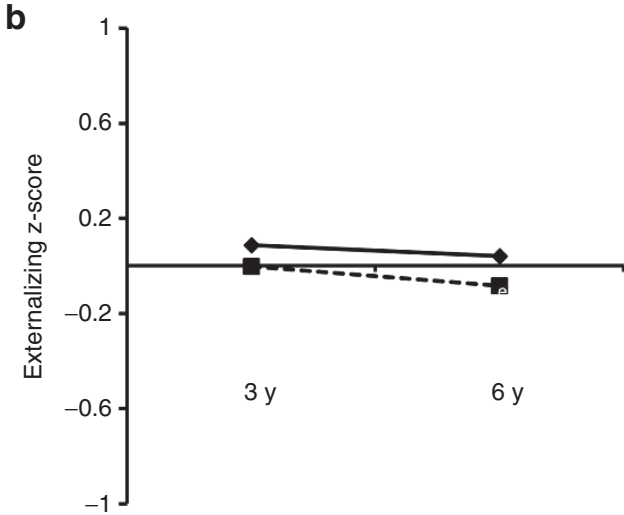

d

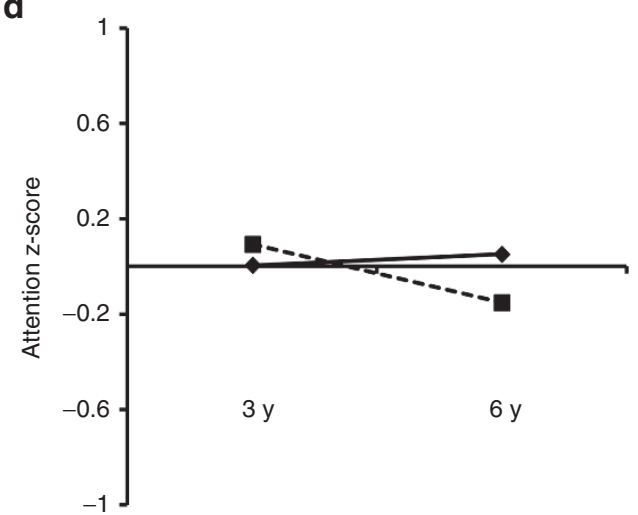

Figure 1. Means of standardized: internalizing behaviors (a); externalizing behaviors (b) anxious subscale (c); attention problems (d) at 3 and 6 y or age according to serotonin reuptake inhibitor exposure in user. The broken line represents exposed children and the solid line represents unexposed children. * indicates a significant group difference at the $95 \%$ confidence level as reported by the repeated measure ANOVA. There were no significant groups by time interactions. 
Figure 1 illustrates the mean scores in internalizing (a subscale examining the extent to which children direct their emotional responses, which includes an assessment of anxiety and depressed behaviors) externalizing (a subscale that examines the degree of aggression, delinquency, and hyperactivity) as well as the subscales that more directly assess children's levels of anxiety and attention by exposure status at both ages 3 and 6 . Increased levels of internalizing (mean $\mathrm{Z}$-score for exposed children was 0.28 at $3 \mathrm{y}$ and 0.22 at $6 \mathrm{y}$ vs. -0.16 and -0.18 in unexposed) (Figure 1a) and anxious behaviors (mean Z-score for exposed children was 0.37 at $3 \mathrm{y}$ and 0.15 at $6 \mathrm{y}$ vs. -0.26 and -0.14 in unexposed children) (Figure 1c) were observed in SRI-exposed children (ANOVA model results $F=7.52, P=0.0072$ and $F=7.91$, $P=0.0058$, respectively). No significant group differences in externalizing behaviors (mean Z-score for exposed children was 0.0 at $3 \mathrm{y}$ and -0.08 at $6 \mathrm{y}$ vs. 0.09 and 0.04 in unexposed children) and attention problems (mean Z-score for exposed children was 0.09 at $3 y$ and -0.15 at $6 y$ vs. 0.01 and 0.05 in unexposed children) were observed between exposed and unexposed children (Figure $1 \mathbf{b}(F=0.43, P=0.5144)$ and $1 \mathrm{D}(F=0.13, P=0.7220)$, respectively). No significant time by group interactions were observed for any of the child behaviors.

Using multilevel mixed model regression analysis, we observed that in utero SRI exposure was associated with significantly higher scores on the internalizing behavior $(\beta=0.38$ $(0.01,0.79))$ and anxious behaviors subscales $(\beta=0.49(0.04$, $0.94)$ ). These positive and significant associations persisted when controlling for concurrent maternal depression and during the second and third trimester and 6 mo postpartum, delivery by cesarean section, child sex, use of other psychotropic medicine during pregnancy, drinking alcohol during pregnancy, and maternal education (Table 4). There were no statistically significant differences in any of our outcomes by child sex. There were also no differences in externalizing behaviors or attention problems according to SRI exposure status. Concurrent maternal depression (maternal depression when the child was 3 and/or 6) was statistically significantly associated with increased levels of internalizing $(\beta=0.64$ $(0.24,1.05))$ and externalizing symptoms $(\beta=0.87(0.47$, $1.27)$ ) in children and increased anxious behaviors $(\beta=0.53$ $(0.08,0.98))$.

\section{DISCUSSION}

Our results suggest that in utero exposure to maternal mood disturbances and to the antidepressants used to manage these symptoms are associated with increased levels of internalizing behaviors and anxiety at school entry. Children who were exposed to SRIs in utero were reported to have more anxious and internalizing behaviors at $3 \mathrm{y}$ of age and this pattern persists at $6 \mathrm{y}$ of age. There was no interaction with time, suggesting that children do not outgrow these behaviors by age 6 . Moreover, in utero SRI exposure did not appear to influence risk for externalizing and attention problems, while maternal depressive symptoms during childhood were associated with increased reports of these behaviors. Significantly more exposed children in our cohort reached clinically significant thresholds for anxiety and internalizing behaviors at 3 and $6 y$ of age; however, we still cannot rule out that this is the result of the underlying maternal depression.

Our findings are consistent with SRI-related behavioral changes observed in animal models that reflect the effects of early changes in central serotonin signaling associated with SRI antidepressant exposure at developmental times comparable with the human third trimester $(8,12-14)$. Our results are also consistent with the previous findings reporting no differences in externalizing and attention behaviors in SRI-exposed animals $(13,14)$ and children $(15,16)$. The lack of association between SRI exposure in utero and externalizing and attention behaviors was expected based on previous reports, and follows from the hypothesized biological mechanism of the downregulation of the developing fetus' serotonergic system (17). In a mature brain, acute SRI exposure may have an inverse modulatory effect whereby it upregulates $5 \mathrm{HT}$ and downregulates norepinephrine-locus coeruleus (NE-LC) (17). In a rodent model, Maciag et al. (14) reported downregulated 5HT-raphe circuit function following citalopram exposure during a period analogous to the human third trimester, whereas enhanced NE-LC system function has been reported following neonatal citalopram administration (18). Such early (or fetal) exposure leading to increased locus ceruleus (NE-LC) function raises an intriguing question of whether anxious childhood behavior in exposed children may also reflect abnormal noradrenergic (NE) transmission (19). The developmental effects of altered NE-LC system and underlying mechanisms associated with such signal modulation remains to be demonstrated in humans with in utero exposure to SRIs.

Table 4. Results from multilevel mixed effects regression models, $\beta$-coefficients ( $95 \% \mathrm{Cl}$ )

\begin{tabular}{|c|c|c|c|c|}
\hline Variable & $\begin{array}{c}\text { Externalizing } \\
\text { subscale (z-scores) }\end{array}$ & $\begin{array}{c}\text { Internalizing } \\
\text { subscale (z-scores) }\end{array}$ & $\begin{array}{l}\text { Anxious behaviors } \\
\text { subscale (z-scores) }\end{array}$ & $\begin{array}{c}\text { Attention } \\
\text { problems (z-scores) }\end{array}$ \\
\hline \multicolumn{5}{|l|}{ Crude } \\
\hline SRI exposure & $-0.11(-0.43,0.21)$ & $0.42(0.12,0.72)$ & $0.44(0.13,0.75)$ & $-0.08(-0.36,0.19)$ \\
\hline \multicolumn{5}{|l|}{ Adjusted $^{a}$} \\
\hline SRI exposure & $-0.17(-0.57,0.22)$ & $0.38(0.01,0.79)$ & $0.49(0.04,0.94)$ & $0.12(-0.32,0.56)$ \\
\hline
\end{tabular}

Bold means significant at 95\% confidence level.

adjusted for child sex, maternal depression during the second and third trimester of pregnancy and 6 mo postpartum, delivery by cesarean section, maternal consumption of alcohol

during pregnancy, maternal education, use of other psych meds during pregnancy, and child age when the data were collected at 3 and $6 \mathrm{y}$.

$\mathrm{Cl}$, confidence interval. 


\section{Articles | Hanley et al.}

In human studies, distinguishing the impact of maternal mood disturbances from in utero SRI exposure remains challenging. Previous research has illustrated that the duration of maternal depression and number of depressive episodes predicts lower IQ and language scores in fluoxetine-exposed children (15-70 mo) (20). At 3 y of age, both in utero SRI exposure and concurrent maternal mood equally predicted increased internalizing behaviors (21). At $4 \mathrm{y}$, behavioral disturbances in prenatally SRI exposed children in another cohort were also influenced by maternal mood symptoms $(15,16)$. Our current findings add longitudinal data that indicates that in utero SRI exposure is associated with sustained increases in internalizing behaviors beyond early childhood.

At this point, it remains unclear whether increased anxious behaviors represent an emerging clinically relevant mood disorder in children with in utero SRI exposure. Anxiety is one of the most common debilitating lifetime psychiatric disorders occurring in $5-20 \%$ of individuals, with symptoms frequently emerging in middle to late adolescence $(22,23)$. In early childhood, these symptoms are expressed as behavioral inhibition, reflecting a tendency to withdraw from novel social situations, heightened vigilance, and fear (24). Such inhibition may represent a potential endophenotype that may evolve into an anxiety disorder in adolescence. Whether our findings point to the effects of early life shifts in central 5HT signaling, secondary to in utero SRI exposure, with a clinically significant condition in later childhood remains to be determined.

A number of key limitations should be acknowledged. We cannot rule out that the relationship reported between SRI exposure in utero and childhood behaviors is a result of confounding by the underlying maternal depression. Given that our behavioral outcomes are based on maternal report, there is some risk of differential outcome reporting by maternal mood or SRI exposure status. The extent of this potential influence is difficult to quantify as there is conflicting evidence in the literature, with some research suggesting that anxious parents are overly pessimistic and biased in their reporting of their anxious children's behaviors (25) while a recent study has illustrated that neither maternal depression nor anxiety contributes significantly to maternal ratings of their children as compared to independent and blinded observer ratings (26). We are also unable to control for confounding by maternal genetic status that might have predisposed a woman to develop a mood disorder (which was then treated with an SRI), and might be heritable also predisposing her child to increased internalizing behaviors. Thus, our findings could be related to a genetic predisposition towards internalizing behaviors and anxiety, rather than an effect of the drug or maternal depression. Finally, we were unable to examine the relationship between the timing, or the duration, of the SRI exposure and childhood behavioral outcomes, as the majority of our mothers using SRI (80\%) did so for more than $200 \mathrm{~d}$ of their pregnancy.

Our results suggest that in utero SRI exposure is associated with increased internalizing and anxious behaviors at an early school age. However, equally important is our finding that concurrent exposure to maternal depression during early childhood was also associated with increased anxious, internalizing as well as externalizing behaviors, even in the presence of continued maternal treatment with an SRI. We report a sustained increase in child behavioral disturbances despite the fact that two thirds (72.7\%) of our mothers who used SRI treatment in pregnancy were still on SRI when their child was $6 \mathrm{y}$ old. These findings raise critical questions about the longterm benefit, or lack thereof of SRI treatment for perinatal mood disorders. SRIs are prescribed to pregnant women with the expectation they will improve maternal mental health, and thus also to confer benefits on the developing fetus and child. Given current rates of use of antidepressants during pregnancy (3) and the concerns about childhood and adolescent anxiety (27), a clearer understanding of the long-term impact of in utero SRI exposure on children's mental health is needed to shape care for mothers with mood disorders and their children.

\section{METHODS}

In this longitudinal cohort study, 191 women were recruited (258 were approached) during their second trimester of pregnancy (mean gestational age $25.7 \mathrm{wk}$ ) from community midwife clinics, family physician clinics, and a reproductive mental health clinic in metropolitan Vancouver (British Columbia, Canada). Seventysix mothers were using SRIs. Of these mother-child pairs, 110 had complete data on child outcomes at 3 and 6 y of age (44 children exposed to SRIs vs. 66 not exposed). We examined the 81 mothers and children who had incomplete data at 3 and 6 y and they were similar in every respect except that children with incomplete data had a significantly different gestational age at birth (39.14 vs. $39.7 \mathrm{wk} ;=0.035)$ and were more likely to be male ( 56 vs. $39.1 \%$; $P=0.023)$.

Among mothers using SRIs, the most common drug used was paroxetine (Table 5) and the mean duration of exposure for all SRIs spanned most or almost all of the pregnancy. Informed consent was obtained from all mothers and the study was approved by the University of British Columbia Research Ethics Board and the BC Women's Hospital Research Review Committee. All SRI exposed mothers were already on antidepressants at the time of conception and had been diagnosed with an Axis I mood disorder by their psychiatrist or family physician prior to entering the study.

Inclusion criteria for this study were: singleton pregnancy, confirmed gestational age at birth, ability to give informed consent, and no fetal anomalies that were detected by antenatal ultrasound. Exclusion criteria included the presence of a maternal bipolar disorder, illicit drug use or abuse and significant maternal medical, obstetrical, or fetal conditions.

Table 5. Specific SRIs ( $n$ ), prenatal dose (range), and length of prenatal exposure

\begin{tabular}{lccc} 
SRI antidepressants & $\begin{array}{c}\text { Number } \\
(\%)\end{array}$ & $\begin{array}{c}\text { Days of prenatal } \\
\text { exposure, mean (SD) }\end{array}$ & $\begin{array}{c}\text { Range (days } \\
\text { of exposure) }\end{array}$ \\
\hline Fluoxetine & $5(11.4)$ & $228.6(53.2)$ & $144-267$ \\
Paroxetine & $16(36.4)$ & $228.6(53.2)$ & $61-292$ \\
Sertraline & $7(15.9)$ & $219.7(91.1)$ & $65-284$ \\
Venlafaxine & $10(22.7)$ & $246.6(73.0)$ & $41-287$ \\
Citalopram & $6(13.6)$ & $238.2(76.4)$ & $94-290$ \\
All SRIs & $44(100)$ & $235.0(70.0)$ & $41-294$ \\
\hline
\end{tabular}

SRI, serotonin reuptake inhibitor. 


\section{Maternal Characteristics and Neonatal Data}

Demographics, reproductive and medical history, and information regarding prescribed medications were obtained at the time of enrollment (mean $25.7 \mathrm{wk}$ gestation), at $36 \mathrm{wk}$ gestation, and 6 mo postpartum. Data on neonatal outcomes at birth were obtained from the neonatal health records including gestational age at birth, birth weight, length, head circumference, Apgar scores at 1 and $5 \mathrm{~min}$, and whether the infant exhibited symptoms of postnatal adaptation syndrome-a cluster of symptoms reported in $\sim 30 \%$ of neonates exposed to SRIs in utero (28) including rapid breathing, respiratory distress, jitteriness, and abnormal tone (29-32).

\section{Maternal Depression and Anxiety}

Maternal depressed mood was assessed using the clinician-rated Hamilton Rating Scale for Depression (HAMD) (33) and maternal anxiety was assessed using the Hamilton Rating Scale for Anxiety (HAMA) (34) at the time of recruitment (mean $25.7 \mathrm{wk}$ gestation) and during the third trimester of pregnancy (mean $34.6 \mathrm{wk}$ gestation) and again at 6 mo postpartum (mean infant age $26.7 \mathrm{wk}$ ) and when the child was 6 y old (mean child age $6.06 \mathrm{y}$ ). At 3 y of age (mean age $3.64 \mathrm{y}$ ), measures of maternal depression and anxiety were obtained by self-report using the Beck depression and anxiety inventories. The HAMD is a 21-item clinician rated scale that measures the severity of depression in adults, adolescents, and children with a range from 0 to 63. The HAMA is a 14-item scale with a range from 0 to 56 (33). The Beck depression and anxiety inventories are 21 -item multiple-choice self-report questionnaires designed to assess the severity of depression and anxiety. Both have a range from 0 to $63(35,36)$.

\section{Child Behavioral Outcomes}

At $3 \mathrm{y}$ of age, maternal report of child behavior was obtained using the Child Behavior Checklist (CBCL 1.5-5) (37). The CBCL provides a standardized rating of behavior in children aged 1.5-5 y and yields a total problem score, externalizing and internalizing scores, and subscale scores. At 6 y of age, mothers completed the MacArthur Health and Behavior Questionnaire (HBQ-P), which yielded measures of internalizing, externalizing, over anxious, and inattention behaviors. The HBQ was derived from the Ontario Child Health Study Measure designed to map on DSM-II_R symptom criteria consistent with the dimensions of internalizing and externalizing behaviors (38). The HBQ-P has strong psychometric properties and has been used to assess child mental health across multiple ages from 4.5 into adolescence (39).

\section{Statistical Analysis}

To compare 3- and 6-y behavioral outcomes, we standardized the scores from the CBCL and the HBQ-P and used $\mathrm{z}$-scores of both scales. Crude differences in maternal, newborn characteristics, and CBCL and HBQ-P scores were compared between mothers and children exposed to SRIs and those unexposed using $t$-tests (continuous variables) or $\chi^{2}$ tests for continuous or categorical variables respectively. Proportions of children who exceeded a validated clinically significant threshold for the internalizing and externalizing subscales (a score of 70 or higher for the CBCL scales and a threshold of 0.71 for internalizing and 0.68 for externalizing on the HBQ) were compared again according to exposure status (39).

Repeated measures ANOVA was used to examine group differences (SRI exposed vs. unexposed) and time ( 3 and 6 y) by group differences in child behaviors. We then used multilevel mixed effects models with a random intercept to examine our longitudinal data for each child for each outcome, as we had repeated measures of internalizing, externalizing, anxiety and attention for each child. Multilevel mixed effects regression modeling allowed us to take advantage of our repeated measures data while adjusting for maternal depression or anxiety (during the second and third trimester, 6 mo postpartum, and when the child was 3 and 6 y old). Cut-off scores of 17 or higher on the HAMD, HAMA, and Beck scales were used to create dichotomous variables indicating that the mother was experiencing clinically significant depression or anxiety symptoms (40). Both maternal anxiety and depression were examined; however our final analytic models only controlled for depression as including maternal anxiety in the model did not meaningfully change the effect size of the SRI exposure variable (defined as a greater than $10 \%$ change). We also adjusted for sex of the child, maternal drinking during pregnancy, mode of delivery (cesarean section), and prenatal use of other psychotropic medications, and maternal education. Maternal smoking status during pregnancy was obtained, but only two mothers reported smoking, so it was not controlled for.

\section{ACKNOWLEDGMENTS}

We would like to thank the mothers and their infants who participated and contributed to this work.

\section{STATEMENT OF FINANCIAL SUPPORT}

G.E.H. was supported by the Canadian Institutes for Health Research, the Michael Smith Foundation for Health Research (British Columbia, Canada), the Women's Health Research Institute (Vancouver, Canada) and Neurodevnet (Canada). T.F.O. is the R. Howard Webster Professor in Early Child Development at the University of British Columbia and his work is supported by the Child and Family Research Institute and the Canadian Institutes for Health Research. This study was supported by the Child and Family Research Institute (UBC) and the Canadian Institutes of Health Research (MOP-57837). The funders had no role in the design and conduct of the study; collection, management, analysis and interpretation of the data; and preparation, review, or approval of the manuscript.

Disclosure: The authors report no conflict of interest.

\section{REFERENCES}

1. Casper RC, Gilles AA, Fleisher BE, Baran J, Enns G, Lazzeroni LC. Length of prenatal exposure to selective serotonin reuptake inhibitor (SSRI) antidepressants: effects on neonatal adaptation and psychomotor development. Psychopharmacology (Berl) 2011;217:211-9.

2. Galbally M, Lewis AJ, Buist A. Developmental outcomes of children exposed to antidepressants in pregnancy. Aust N Z J Psychiatry 2011;45:393-9.

3. Daw JR, Mintzes B, Law MR, Hanley GE, Morgan SG. Prescription drug use in pregnancy: a retrospective, population-based study in British Columbia, Canada (2001-2006). Clin Ther 2012;34:239-249.e2.

4. Gaspar P, Cases O, Maroteaux L. The developmental role of serotonin: news from mouse molecular genetics. Nat Rev Neurosci 2003;4:1002-12.

5. Homberg JR, Schubert D, Gaspar P. New perspectives on the neurodevelopmental effects of SSRIs. Trends Pharmacol Sci 2010;31:60-5.

6. Rampono J, Simmer K, Ilett KF, et al. Placental transfer of SSRI and SNRI antidepressants and effects on the neonate. Pharmacopsychiatry 2009;42:95-100.

7. Popa D, Léna C, Alexandre C, Adrien J. Lasting syndrome of depression produced by reduction in serotonin uptake during postnatal development: evidence from sleep, stress, and behavior. J Neurosci 2008;28:3546-54.

8. Ansorge MS, Zhou M, Lira A, Hen R, Gingrich JA. Early-life blockade of the 5-HT transporter alters emotional behavior in adult mice. Science 2004;306:879-81.

9. Hensler JG. Serotonergic modulation of the limbic system. Neurosci Biobehav Rev 2006;30:203-14.

10. Simpson KL, Weaver KJ, de Villers-Sidani E, et al. Perinatal antidepressant exposure alters cortical network function in rodents. Proc Natl Acad Sci USA 2011;108:18465-70.

11. Zhang J, Dennis KA, Darling RD, et al. Neonatal citalopram exposure decreases serotonergic fiber density in the olfactory bulb of male but not female adult rats. Front Cell Neurosci 2013;7:67.

12. Ansorge MS, Morelli E, Gingrich JA. Inhibition of serotonin but not norepinephrine transport during development produces delayed, persistent perturbations of emotional behaviors in mice. J Neurosci 2008;28: 199-207.

13. Lira A, Zhou M, Castanon N, et al. Altered depression-related behaviors and functional changes in the dorsal raphe nucleus of serotonin transporter-deficient mice. Biol Psychiatry 2003;54:960-71. 


\section{Articles | Hanleyet al.}

14. Maciag D, Simpson KL, Coppinger D, et al. Neonatal antidepressant exposure has lasting effects on behavior and serotonin circuitry. Neuropsychopharmacology 2006;31:47-57.

15. Misri S, Reebye P, Kendrick K, et al. Internalizing behaviors in 4-year-old children exposed in utero to psychotropic medications. Am J Psychiatry 2006;163:1026-32.

16. Oberlander TF, Reebye P, Misri S, Papsdorf M, Kim J, Grunau RE. Externalizing and attentional behaviors in children of depressed mothers treated with a selective serotonin reuptake inhibitor antidepressant during pregnancy. Arch Pediatr Adolesc Med 2007;161:22-9.

17. West CH, Ritchie JC, Boss-Williams KA, Weiss JM. Antidepressant drugs with differing pharmacological actions decrease activity of locus coeruleus neurons. Int J Neuropsychopharmacol 2009;12:627-41.

18. Darling RD, Alzghoul L, Zhang J, et al. Perinatal citalopram exposure selectively increases locus ceruleus circuit function in male rats. J Neurosci 2011;31:16709-15.

19. Devoto P, Flore G, Saba P, Fà M, Gessa GL. Stimulation of the locus coeruleus elicits noradrenaline and dopamine release in the medial prefrontal and parietal cortex. J Neurochem 2005;92:368-74.

20. Nulman I, Rovet J, Stewart DE, et al. Child development following exposure to tricyclic antidepressants or fluoxetine throughout fetal life: a prospective, controlled study. Am J Psychiatry 2002;159:1889-95.

21. Oberlander TF, Papsdorf M, Brain UM, Misri S, Ross C, Grunau RE. Prenatal effects of selective serotonin reuptake inhibitor antidepressants, serotonin transporter promoter genotype (SLC6A4), and maternal mood on child behavior at 3 years of age. Arch Pediatr Adolesc Med 2010;164:444-51.

22. Beesdo K, Knappe S, Pine DS. Anxiety and anxiety disorders in children and adolescents: developmental issues and implications for DSM-V. Psychiatr Clin North Am 2009;32:483-524.

23. Briggs-Gowan MJ, Horwitz SM, Schwab-Stone ME, Leventhal JM, Leaf PJ. Mental health in pediatric settings: distribution of disorders and factors related to service use. J Am Acad Child Adolesc Psychiatry 2000;39:841-9.

24. Pine DS, Helfinstein SM, Bar-Haim Y, Nelson E, Fox NA. Challenges in developing novel treatments for childhood disorders: lessons from research on anxiety. Neuropsychopharmacology 2009;34:213-28.

25. Cobham VE, Dadds MR, Spence SH. Anxious children and their parents: what do they expect? J Clin Child Psychol 1999;28:220-31.

26. Udy CM, Newall C, Broeren S, Hudson JL. Maternal expectancy versus objective measures of child skill: evidence for absence of positive bias in mothers' expectations of children with internalizing disorders. J Abnorm Child Psychol 2014;42:439-51.
27. Mychailyszyn MP, Mendez JL, Kendall PC. School functioning in youth with and without anxiety disorders: comparisons by diagnosis and comorbidity. Sch Psychol Rev 2010;39:106-21.

28. Oberlander TF, Misri S, Fitzgerald CE, Kostaras X, Rurak D, Riggs W. Pharmacologic factors associated with transient neonatal symptoms following prenatal psychotropic medication exposure. J Clin Psychiatry 2004;65:230-7.

29. Chambers CD, Johnson KA, Dick LM, Felix RJ, Jones KL. Birth outcomes in pregnant women taking fluoxetine. N Engl J Med 1996;335:1010-5.

30. Davis RL, Rubanowice D, McPhillips H, et al.; HMO Research Network Center for Education, Research in Therapeutics. Risks of congenital malformations and perinatal events among infants exposed to antidepressant medications during pregnancy. Pharmacoepidemiol Drug Saf 2007;16:1086-94.

31. Costei AM, Kozer E, Ho T, Ito S, Koren G. Perinatal outcome following third trimester exposure to paroxetine. Arch Pediatr Adolesc Med 2002;156:1129-32.

32. Källén B. Neonate characteristics after maternal use of antidepressants in late pregnancy. Arch Pediatr Adolesc Med 2004;158:312-6.

33. Hamilton M. A rating scale for depression. J Neurol Neurosurg Psychiatry 1960;23:56-62.

34. Hamilton M. The assessment of anxiety states by rating. Br J Med Psychol 1959;32:50-5.

35. Beck AT, Steer RA, Garbin MG. Psychometric properties of the Beck Depression Inventory: Twenty-five years of evaluation. Clin Psychol Rev 1988;8:77-100.

36. Beck AT, Epstein N, Brown G, Steer RA. An inventory for measuring clinical anxiety: psychometric properties. J Consult Clin Psychol 1988;56:893-7.

37. Achenbach TM. Manual for the Child Behavior Checklist/2-3 and 1992 Profile. Department of Psychiatry, University of Vermont: Burlington, Vermont, 1992.

38. Boyle MH, Offord DR, Racine Y, Fleming JE, Szatmari P, Sanford M. Evaluation of the revised Ontario Child Health Study scales. J Child Psychol Psychiatry 1993;34:189-213.

39. Lemery-Chalfant K, Schreiber JE, Schmidt NL, Van Hulle CA, Essex MJ, Goldsmith HH. Assessing internalizing, externalizing, and attention problems in young children: validation of the MacArthur HBQ. J Am Acad Child Adolesc Psychiatry 2007;46:1315-23.

40. Zimmerman M, Martinez JH, Young D, Chelminski I, Dalrymple K. Severity classification on the Hamilton Depression Rating Scale. J Affect Disord 2013;150:384-8. 